\title{
Corticosteroid-Induced Neural Remodeling Predicts Behavioral Vulnerability and Resilience
}

\author{
Shannon L. Gourley, ${ }^{1,2,3,4 \star}$ Andrew M. Swanson, ${ }^{1,2,3 \star}$ and Anthony J. Koleske ${ }^{4,5,6}$ \\ ${ }^{1}$ Department of Pediatrics, Emory School of Medicine, ${ }^{2}$ Neuroscience Graduate Program, and ${ }^{3}$ Yerkes National Primate Research Center, Emory University, \\ Atlanta, Georgia 30322, and ${ }^{4}$ Department of Molecular Biophysics and Biochemistry, ${ }^{5}$ Interdepartmental Neuroscience Program, and ${ }^{6}$ Department of \\ Neurobiology, Yale School of Medicine, Yale University, New Haven, Connecticut 06520
}

Neurons in distinct brain regions remodel in response to postnatal stressor exposure, and structural plasticity may underlie stressrelated modifications in behavioral outcomes. Given the persistence of stress-related diseases such as depression, a critical next step in identifying the contributions of neural structure to psychopathology will be to identify brain circuits and cell types that fail to recover from stressor exposure. We enumerated dendritic spines during and after chronic stress hormone exposure in hippocampal CA1, deep-layer prefrontal cortex, and the basal amygdala and also reconstructed dendritic arbors of CA1 pyramidal neurons. Corticosterone modified dendritic spine density in these regions, but with the exception of the orbitofrontal cortex, densities normalized with a recovery period. Dendritic retraction of hippocampal CA1 neurons and anhedonic-like insensitivity to a sucrose solution also persisted despite a recovery period. Using mice with reduced gene dosage of p190rhogap, a cytoskeletal regulatory protein localized to dendritic spines, we next isolated structural correlates of both behavioral vulnerability (spine elimination) and resilience (spine proliferation) to corticosterone within the orbital cortex. Our findings provide novel empirical support for the perspective that stress-related structural reorganization of certain neuron populations can persist despite a "recovery" period from stressor exposure and that these modifications may lay a structural foundation for stressor vulnerability — or resiliency-across the lifespan.

\section{Introduction}

Stress hormones, particularly corticosterone (CORT), regulate postnatal dendritic and dendritic spine morphology in distinct brain regions including the prefrontal cortex, hippocampus, and amygdala. Structural remodeling in response to chronic stressor exposure is thought to contribute to aspects of stress-related psychiatric disease. For example, stress-related prefrontal cortical dendritic reorganization predicts impairments in attentional function in rodents (Liston et al., 2006), and reductions in hippocampal volume correlate with the lifetime duration of depression in humans (Sheline et al., 1999). Landmark investigations

Received May 3, 2012; revised Dec. 19, 2012; accepted Dec. 20, 2012.

Author contributions: S.L.G. and A.J.K. designed research; S.L.G., A.M.S., and A.J.K. performed research; S.L.G., A.M.S., and A.J.K. analyzed data; S.L.G., A.M.S., and A.J.K. wrote the paper.

*S.L.G. and A.M.S. contributed equally to this work.

The authors declare no competing financial interests.

This work was supported by the Interdisciplinary Research Consortium on Stress, Self-Control, and Addiction (UL1-DE19586 and the NIH Roadmap for Medical Research/Common Fund, AA017537) (S.L.G., A.J.K.); Public Health Service Grant NS39475 (A.J.K.); Children's Healthcare of Atlanta (S.L.G.); the Microscopy Core of the Emory Neuroscience National Institute of Neurological Disorders and Stroke Core Facilities Grant P30 NS055077; the EmoryEgleston Children's Research Center; and National Institute on Drug Abuse Grant T32 DA015040 (Primary Investigator: M. J. Kuhar). The components of this project performed at the Yerkes National Primate Research Center were also funded by the National Center for Research Resources Grant P51 RR165 and are currently supported by the Office of Research Infrastructure Programs/OD Grant P51 0D11132. We thank X.-Y. Ye and M. Kerrisk for their assistance and Drs. K. Collins, Y.-C. Lin, G. Aghajanian, and J. Taylor for feedback throughout. Dr. J. Settleman kindly provided p190rhogap ${ }^{+/-}$mice.

Correspondence should be addressed to either of the following: Anthony J. Koleske, 333 Cedar Street, SHMC-E31, New Haven, CT 06420-8024, E-mail: anthony.koleske@yale.edu; or Shannon L. Gourley, 954 Gatewood Road Northeast, Atlanta, GA 30329. E-mail: Shannon.l.gourley@emory.edu.

DOI:10.1523/JNEUROSCI.2138-12.2013

Copyright $\odot 2013$ the authors $\quad 0270-6474 / 13 / 333107-06 \$ 15.00 / 0$ that characterized the consequences of chronic stressor exposure on pyramidal neurons within prefrontal-hippocampal-amygdala circuits largely focused on immediate, rather than persistent, consequences (Woolley et al., 1990; Sousa et al., 2000; Wellman, 2001; Vyas et al., 2002). A comprehensive characterization of structural modifications that persist beyond the period of exposure represents a critical next step in understanding mechanisms of lifetime vulnerability and resilience to stress-related psychiatric disease.

Here we focused on cortico-hippocampal-amygdalar structural reorganization in response to prolonged exposure to the major stress hormone CORT. We aimed to isolate structural modifications that failed to recover despite a washout period. We hypothesized that these modifications would provide a structural foundation for the development and persistence of anhedonic-like behaviors, a hallmark symptom of depression that is thought to involve corticohippocampal-amygdalar circuits (Der-Avakian and Markou, 2012).

Structural remodeling in the central nervous system is orchestrated by Rho family GTPases, including RhoA (Rho), Rac1, and Cdc42, which coordinate the actin cytoskeletal rearrangements that are required for spinogenesis or spine elimination. Rho regulates actin polymerization and actomyosin contractility-for example, expression of constitutively active Rho leads to dendritic spine loss (Tashiro et al., 2000), and Rho activation during the late postnatal period disrupts synapse stability (Sfakianos et al., 2007). Rho is inhibited by p190RhoGAP, which is localized to dendritic spines and activated by integrin receptor engagement with extracellular matrix proteins (Arthur et al., 2000; Lamprecht et al., 2002; Hernández et al., 2004; Bradley et al., 2006). Thus, we 
also used mice with reduced gene dosage of p190rhogap as a model of structural vulnerability to further isolate cellular predictors of behavioral vulnerability to stress hormone exposure.

\section{Materials and Methods}

Subjects. Male mice were 5-7 weeks old. Wild-type (wt) C57BL/6 mice were purchased from Charles River Laboratories. Transgenic mice expressing thy1-derived GFP (Feng et al., 2000) enabled visualization of dendritic spines. Our final experiment used GFP-expressing p190RhoGAP-deficient mice ( 190rhogap ${ }^{+/-}$), which have $~ 32-40 \%$ less p190RhoGAP protein (Brouns et al., 2000). All were bred on a C57BL/6 background, maintained on a $12 \mathrm{~h}$ light cycle (0700 on), and provided food and water ad libitum unless otherwise indicated. Procedures were Yale and Emory IACUC approved.

CORT exposure. CORT (4-pregnen-11 $\beta$-21-DIOL-3-20-DIONE-21hemisuccinate; Steraloids) was dissolved in water and administered for 20 days ( $25 \mu \mathrm{g} / \mathrm{ml}$ free-base, translating to $\sim 4.97 \mathrm{mg} / \mathrm{kg} / \mathrm{day}$ ). This protocol recapitulates blood CORT levels in mice exposed to chronic restraint stress (Gourley et al., 2008). Mice were euthanized at 20 days or 20 days plus a 1 week washout period.

In a final experiment using GFP-expressing p190rhograp ${ }^{+/-}$and p190rhograp ${ }^{+/+}$mice, $10 \mu \mathrm{g} / \mathrm{ml}$ was used as a subthreshold CORT concentration. This dose is described in text as a "subthreshold CORT."

Biocytin injection of hippocampal neurons. Wild-type mice were deeply anesthetized with pentobarbital and, as described previously (Sfakianos et al., 2007), hippocampal slices $(400 \mu \mathrm{m})$ were prepared and maintained in a standard interface chamber at $33^{\circ} \mathrm{C}$. Individual CA1 pyramidal neurons were injected with $4 \%$ biocytin solution in $2 \mathrm{M}$ sodium acetate solution, pH 7.5. Neurons were injected with 100-300 ms current injections of $5 \mathrm{nA}$ at $1 \mathrm{~Hz}$ for $20 \mathrm{~min}$. Only neurons that maintained a membrane potential and fired action potentials during this entire period were analyzed. After $10 \mathrm{~min}$ of recovery, injected neurons were fixed in $4 \%$ paraformaldehyde overnight, cryoprotected in 30\% sucrose, then resectioned at $40 \mu \mathrm{m}$ and visualized using standard avidin-horseradish peroxidase staining (Vectastain Elite ABC; Vector Laboratories).

Morphometric analysis of dendrites. Z-stack series of individual biocytin-labeled neurons were considered complete only when clean dendrite-free sections were detectable on the far $+\mathrm{Z}$ and $-\mathrm{Z}$ margins. The 5-8 serial sections containing dye-filled neurons were traced sequentially starting at the cell body and moving in plus and minus directions under $100 \times$ magnification using a light microscope with a $Z$ drive. Cells were then reconstructed using Neurolucida software (MicroBrightField). As is standard practice, sections were apposed using landmarks and aligned at high magnification by joining interrupted primary and secondary branches based on position, orientation, and dendrite thickness. Sholl analysis, total dendrite length, and branch point number were determined using NeuroExplorer (MicroBrightField). Neurons were traced by an experimenter blind to group. Two to four neurons were sampled from each mouse; each mouse ( $n=9-11$ /group) was considered an independent sample.

Dendritic spine capture and enumeration. As described (Gourley et al., 2012), fresh GFP-expressing brains were submerged in $4 \%$ paraformaldehyde for $48 \mathrm{~h}$, then transferred to $30 \%(\mathrm{w} / \mathrm{v})$ sucrose, followed by sectioning into $40-\mu \mathrm{m}$-thick sections on a microtome held at $-15^{\circ} \mathrm{C}$. Unobstructed dendritic segments running parallel to the surface of the section were imaged on a spinning disk confocal (VisiTech International) on a Leica microscope. Z-stacks were taken with a $100 \times 1.4$ numerical aperture objective using a $0.1 \mu \mathrm{m}$ step size, sampling above and below the dendrite. After imaging, we confirmed at $10 \times$ that the image was collected from the intended subregions.

Collapsed Z-stacks were analyzed using NIH ImageJ; each protrusion $\leq 4 \mu \mathrm{m}$ was considered a spine (Peters and Kaiserman-Abramof, 1970). Individual planes were evaluated to detect protrusions perpendicular to the Z-stack. Bifurcated spines were considered singular units. To generate density values, spine number for each segment was normalized to the length of the segment.

From cortical and amygdalar neurons, 6-8 independent segments from secondary and tertiary dendritic branches within $50-150 \mu \mathrm{m}$ of the soma
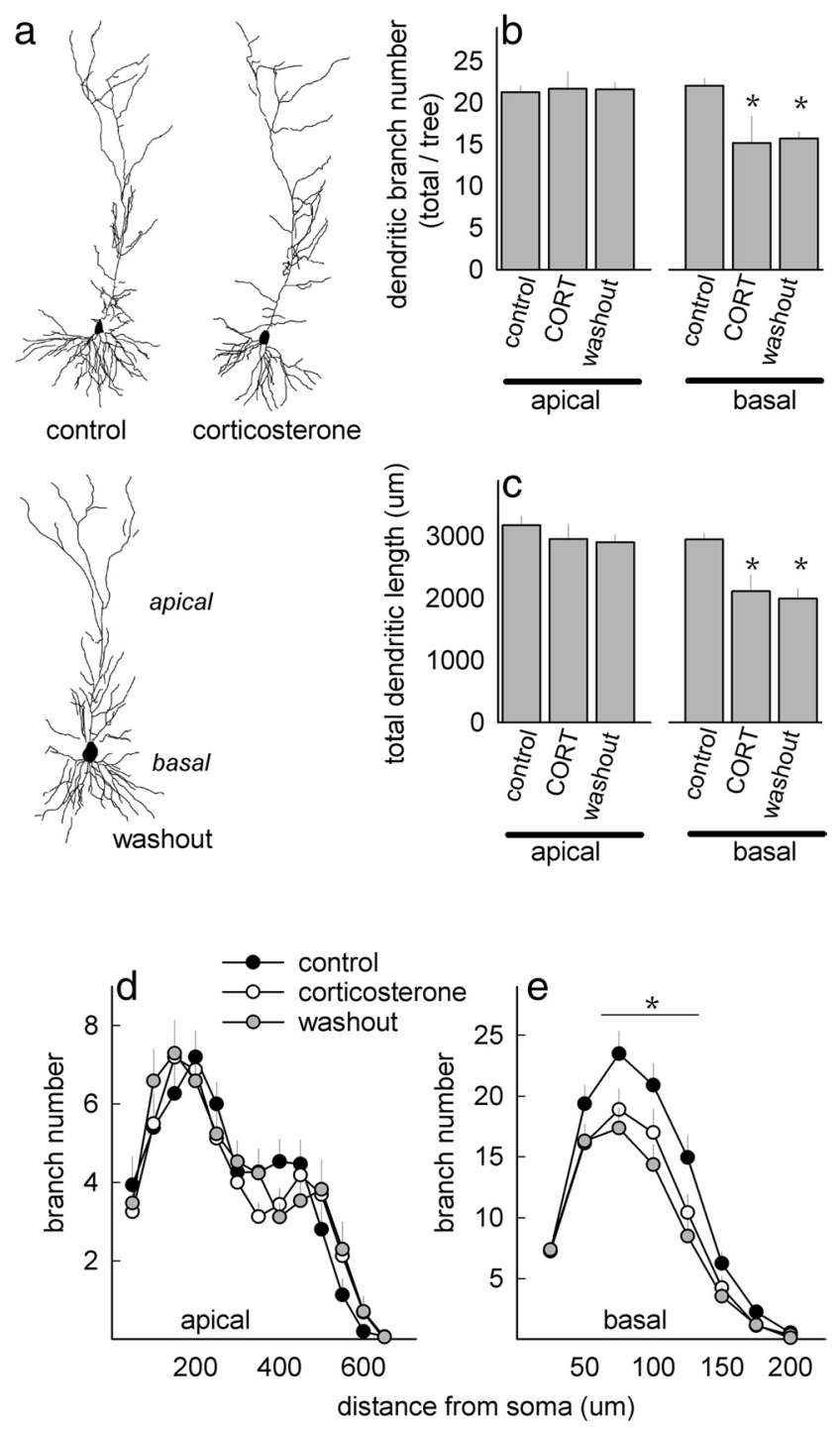

Figure 1. CORT exposure destabilizes CA1 dendritic structure. $\boldsymbol{a}$, Representative CA1 neurons in control, CORT, and washout groups. $\boldsymbol{b}$, CORT reduced dendritic branching in basal, but not apical, trees, and branch points failed to normalize with a washout period. c, Total dendritic length was also diminished in mice with a history of CORT exposure. $d, e$, Sholl analyses revealed no effects on apical dendritic arborization (d), but basal arbors $75-125 \mu \mathrm{m}$ from the cell body simplified after CORT, and they failed to recover with a 1-week washout period (e). Symbols/ bars, means \pm SEM, ${ }^{*} p<0.05$.

were collected. Each group contained 6-8 mice, with each animal contributing a single density value to statistical analyses. Due to the stellate appearance of amygdalar and orbital prefrontal cortex (oPFC) neurons (Liston et al., 2006; Kolb et al., 2008), apical versus basal branches were not distinguished. In the infralimbic cortex (ILc), apical branches were evaluated.

In the hippocampus, CA1 neuronal alignment allows for unambiguous sampling as a function of distance from the soma. Thus, $6-8$ independent basal neurons/mouse were identified, and 1 dendrite/neuron $/ 30$ $\mu \mathrm{m}$ window radiating from the soma was sampled. A single blinded rater scored spines.

Semiautomated dendritic spine reconstruction. To evaluate both spine density and head diameter in GFP-expressing p190rhogap ${ }^{+/-}$samples, $3 \mathrm{D}$ reconstructions were accomplished with the FilamentTracer module of Imaris (Bitplane) as described (Swanger et al., 2011). A dendritic segment $\sim 25 \mu \mathrm{m}$ in length sampled from the oPFC (see above, Dendritic spine capture and enumeration) or basal CA1 (60-90 $\mu \mathrm{m}$ from the soma) was drawn using the AutoDepth function. FilamentTracer processing algorithms centered the segment and determined dendrite diam- 

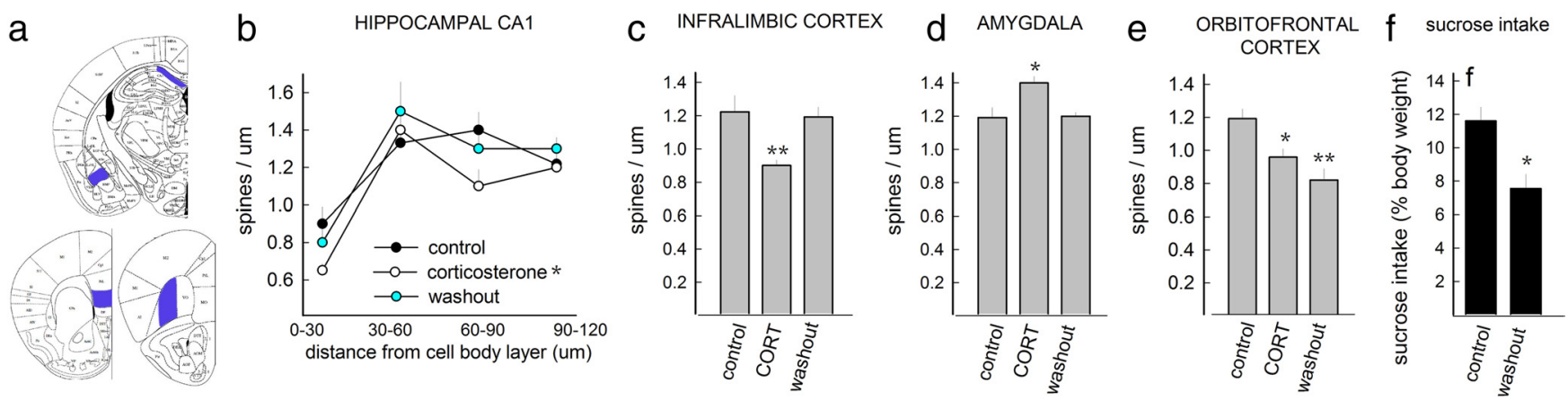

Figure 2. Chronic corticosteroid exposure has regionally selective effects on dendritic spine density. $\boldsymbol{a}$, Sampling sites are highlighted. $\boldsymbol{b}$, Dendritic spines on basal CA1 dendritic arbors were analyzed as a function of distance from the cell body — a main effect indicates that CORT decreased spine density, but densities were restored with a washout period. $c$, CORT also decreased densities on pyramidal neurons in deep-layer ILc, but densities recovered with a washout period. $\boldsymbol{d}$, Densities on pyramidal neurons within the basal amygdala increased after CORT, but again recovered with a washout period. $\boldsymbol{e}, \mathrm{OPFC}$ dendritic spines were eliminated; however, here densities failed to normalize. $f$, A history of CORT exposure also reduced sucrose consumption, despite a washout period, in a model of anhedonia. Symbols/bars, means $\pm \mathrm{SEM},{ }^{*} p<0.05,{ }^{* *} p<0.001$ versus control.

eter. The autodepth function drew dendritic spines along the dendrite. Each spine was then reconstructed in 3D using the FilamentTracer algorithm. A single blinded rater processed all images.

Behavioral modeling. We used a model of anhedonia; $1 \%(\mathrm{w} / \mathrm{v})$ sucrose replaced regular drinking water for 2 days starting 2 days after CORT exposure. Animals were then habituated to water restriction by removing the water bottle for $19 \mathrm{~h}$. Next, mice were again water- restricted overnight, and each mouse was allowed $1-\mathrm{h}$ access to the sucrose solution in its home cage while cage mates were housed in a clean cage in a quiet room. Liquid consumption was recorded, and the next mouse was tested. This approach allows us to evaluate sucrose consumption in the home cage in individual mice while still maintaining standard laboratory group housing (2-5 mice/cage) (Gourley et al., 2008, 2009a). The average water restriction period for each cage was $16 \mathrm{~h}$. The test was repeated the following day with water to confirm that general fluid consumption did not differ between groups.

In the first experiment (Fig. 2), mice were wild type (control vs CORT, $n=6 /$ group); in the second experiment (Fig. 3), GFP-expressing p190rhogap ${ }^{+/-}$and GFP-expressing littermate controls exposed to exogenous CORT or CORT-naive mice (4 groups, $n=7-14$ /group depending on litter composition). These mice were euthanized after test for dendritic spine capture.

Statistical analyses. Sucrose consumption and morphometric measures were analyzed by 1 - or 2-factor ANOVA as appropriate, with repeated measures when values were analyzed as a function of distance from the soma. Post hoc comparisons were made using Tukey's $t$ tests and, when significant, results are indicated graphically. When two groups were compared, two-tailed $t$ tests were used. To highlight whether genotype determined dendritic spine sensitivity to CORT, percent change from baseline (meaning the mean value of CORT-naive mice of the same genotype) was calculated and compared to 0 (no change) by location $t$ test. $p<0.05$ was considered significant, and outliers were excluded.

Spine head diameters were analyzed by Kolmogorov-Smirnov (K-S) comparisons. Because of the high degree of statistical power generated by $\mathrm{K}-\mathrm{S}$ tests, only $p<0.001$ was considered significant.

\section{Results}

\section{Corticosterone simplifies hippocampal CA1 dendrites}

We first approached the issue of CORT-induced structural reorganization by characterizing the dendritic morphology of hippocampal CA1 neurons. As reported previously (MoralesMedina et al., 2009), CORT reduced dendritic branch points, but we localized this effect to basal trees. Notably, dendritic branch points did not recover despite a 1 week CORT washout period $\left(F_{(2,27)}=6.6, p<0.05\right)$ (Fig. $\left.1 a, b\right)$. A history of CORT exposure also reduced basal branch length $\left(F_{(2,21)}=7.4, p=0.004\right.$; apical $p$ values $\geq 0.7$ ] (Fig. 1c), and Sholl analysis indicated that basal arbors simplified $75-125 \mu \mathrm{m}$ from the cell body and did not recover their original complexity (interaction, $F_{(18,225)}=2.5, p<$ 0.001 ). Although there is some evidence that apical trees simplify with stressor exposure (Christian et al., 2011), apical trees were unaffected here (interaction, $p=0.3$ ) (Fig. $1 d, e$ ).

\section{A history of corticosteroid exposure modifies dendritic spines and behavior}

Based on these findings, we investigated dendritic spine density on basal CA1 arbors. Regions of interest for this and subsequent investigations are indicated (Fig. 2a). In CA1, CORT reduced spine density, but unlike CORT-induced dendritic remodeling, spine densities normalized with a 1 week washout period (main effect, $F_{(2,17)}=4.8, p<0.05$; no interactions) (Fig. $\left.2 b\right)$. We note, however, that even if dendritic spine density is normal, fewer dendritic processes in $\mathrm{CAl}$ - as described above - would result in fewer total spines/neuron.

We next expanded our survey to other cortico-limbic structures; CORT reduced ILc spine density as expected (Liu and Aghajanian, 2008), but densities recovered with a washout period $\left(F_{(2,19)}=4.2, p=0.03\right)$ (Fig. $\left.2 c\right)$. In the basal amygdala, CORT elevated spine density; but again, densities normalized with a 1 week washout period $\left(F_{(2,17)}=4.3, p=0.03\right)$ (Fig. $\left.2 d\right)$. In the orbital prefrontal cortex, however, densities declined and failed to recover after a washout period $\left(F_{(2,18)}=4.3, p=0.03\right)$ (Fig. 2e).

Corticosteroid exposure thus has discrete long-term structural consequences. To evaluate behavioral consequences, we measured animals' sucrose consumption in a model of anhedonia. Even 1 week after CORT washout, CORT-exposed mice reduced their sucrose consumption, reflecting a persistent anhedonic-like phenotype $\left(t_{10}=3, p=0.01\right)$ (Fig. $\left.2 f\right)$.

\section{p190RhoGAP determines the behavioral and cellular responses to CORT}

To further isolate the relationship between persistent dendritic spine modifications and long-term behavioral consequences of CORT exposure, we generated GFP-expressing mice with reduced gene dosage of the dendrite stability factor p190rhogap, exposed them to a subthreshold dose of CORT, and evaluated behavioral and structural outcomes. Throughout, oPFC dendritic spine densities and behavioral outcomes were not affected by p190rhogap deficiency, but genotype critically determined the behavioral and cellular response to CORT; control mice were behaviorally unaffected by subthreshold CORT, but p190rhogap-deficient mice developed an 

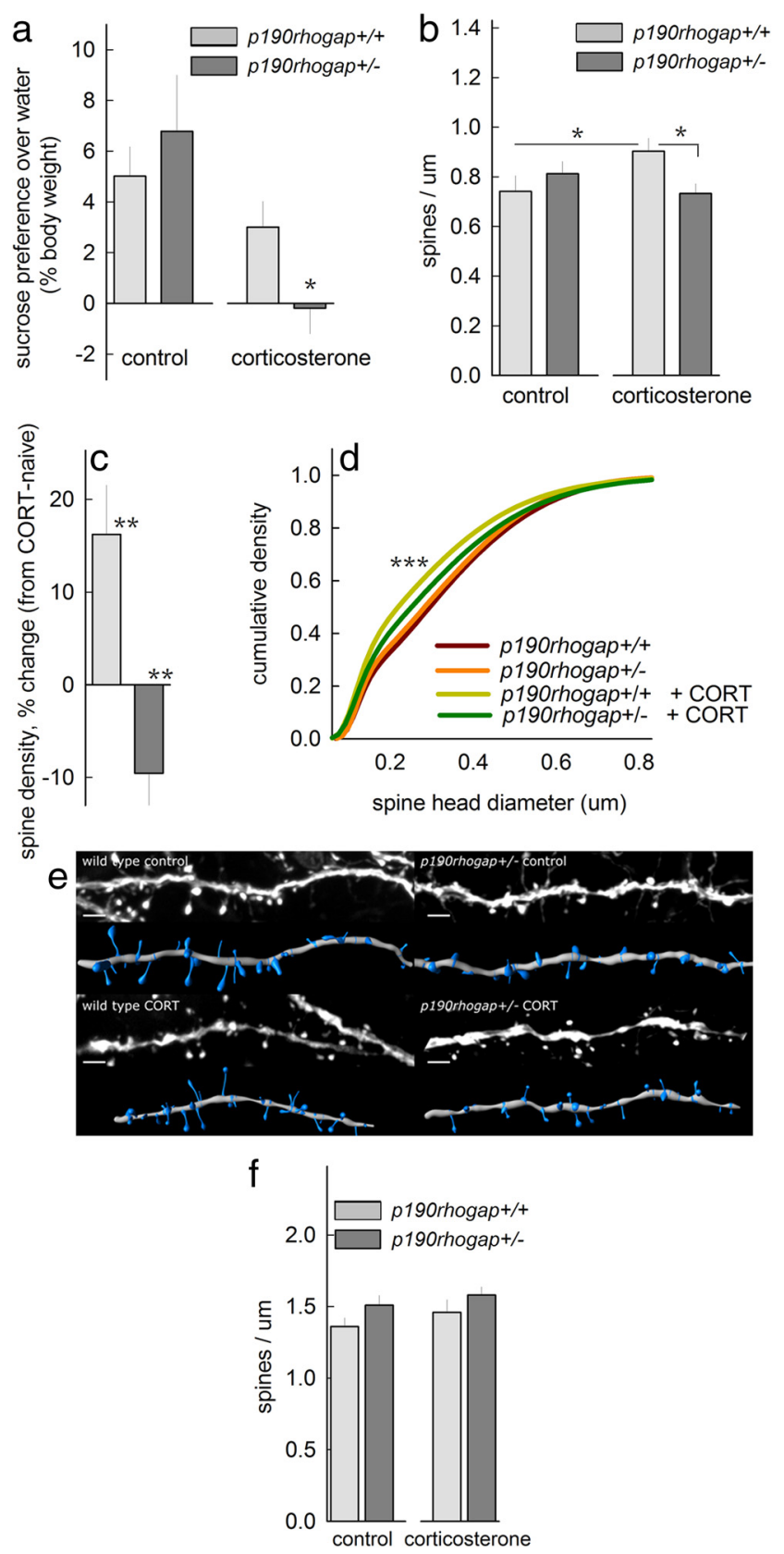

Figure 3. p190RhoGAP determines the OPFC response to CORT. $\boldsymbol{a}$, In a sucrose preference test, p190rhogap ${ }^{+/+}$mice were resilient to subthreshold CORT, showing intact sucrose preference over water. By contrast, p190rhogap ${ }^{+/-}$mice developed anhedonic-like sucrose neglect. $\boldsymbol{b}$, In the OPFC, spine density increased in p190rhogap ${ }^{+/+}$mice, but spines were eliminated in CORT-exposed $p 190$ rhogap ${ }^{+/-}$mice; ${ }^{*} p<0.05$. c, Expressed another way, subthreshold CORT increased oPFC spine density by $>15 \%$ in p190rhogap ${ }^{+/+}$mice but eliminated $\approx 10 \%$ of spines in 190 RhoGAP-deficient mice; ${ }^{* *} p \leq 0.005$ versus 0 .d, CORT-exposed p190rhogap ${ }^{+/+}$mice also had a larger population of oPFC spines with small heads; ${ }^{* * *} p<$ 0.001 versus drug-free p190rhogap ${ }^{+/+} . \boldsymbol{e}$, Representative $\mathrm{OPFC}$ spines with reconstructions. Scale bar, $3 \mu \mathrm{m}$. $f$, As a control, we show that subthreshold CORT spared CA1 dendritic spinesonly a trend for an effect of genotype was noted ( $p=0.08)$. Bars, Group means \pm SEM).

anhedonic-like insensitivity to the sucrose solution (Fig. $3 a$ ), and in parallel oPFC $p$ 190rhogap $^{+/-}$spines were eliminated (Fig. 3b,c) (genotype $\times$ CORT interactions $p<0.04$ ).

By contrast, oPFC spines proliferated in p190rhogap ${ }^{+/+}$ mice exposed to subthreshold CORT (Fig. $3 b-c$ ). Also, subthreshold CORT-exposed p190rhogap ${ }^{+/+}$mice had a larger population of small-headed spines, potentially reflecting new immature protrusions (K-S $p<0.001$ ) (Fig. 3d,e) (Bourne and Harris, 2011).

In the hippocampus, only a trend for an effect of genotype was identified ( $p=0.08$ ), with no detectable response to subthreshold CORT (interaction $\mathrm{F}<1$ ) (Fig. $3 f$ ). Head diameters also did not differ (data not shown).

\section{Discussion}

The ability of neurons to integrate into networks and regulate behavior is determined by the shape and density of dendrites and dendritic spines, the postsynaptic components of most excitatory synapses in the brain. Spines are remarkably plastic-e.g., hippocampal CA3 spines remodel in response to postnatal stressor or corticosteroid exposure (Tata and Anderson, 2010). These modifications may play a role in stress-related mood disorders involving cortico-amygdalo-hippocampal circuits (e.g., depression), but identification of structural modifications that-like stress-related mood disorders-persist beyond the period of stressor exposure remains incomplete. We used transgenic mice expressing thy 1 -derived GFP to isolate and reconstruct CA1, basal amygdalar, and deep-layer prefrontal cortical dendritic spines. Because relatively little is known about the sensitivities of CA1 pyramidal neurons, these cells were also reconstructed in full. Among the cell populations sampled, all remodeled in response to prolonged corticosteroid exposure, but only basal CA1 dendritic arbors and oPFC dendritic spines failed to recover with a corticosteroid washout period.

\section{Hippocampal networks and stress-related structural reorganization}

Hippocampal CA3 neurons are exquisitely sensitive to stressor exposure (Tata and Anderson, 2010), and certain aspects of stress-related impairments in hippocampal-dependent learning and memory may reflect CA3 remodeling (Conrad et al., 1999; McEwen et al., 2012). The CA1 neuronal response to stressors is less well characterized by comparison. This is likely because CA1 neurons are regarded as more resilient- though not stress-insensitive-than their CA3 counterparts, based at least in part on investigations using bolus CORT doses (33-40 mg/kg) that occlude normal circadian CORT cycling (Woolley et al., 1990; Sousa et al., 2000; Morales-Medina et al., 2009). By contrast, the oral CORT protocol used here mimics CORT secretion during restraint stress and leaves circadian cycling intact (Gourley et al., 2008). Oral CORT resulted in dendritic spine elimination and dendritic simplification $75-125 \mu \mathrm{m}$ from the cell body. This region approximates the CA1-subiculum intersection targeted in the ventral hippocampus by projections from the basal amygdala (Pitkänen et al., 2000), raising the possibility that prolonged hyperexcitability of amygdala projections after stressor exposure (Correll et al., 2005) may be a presynaptic mechanism that results in hippocampal reorganization.

Basal dendritic arbors remained simplified despite a corticosteroid washout period. How might this relate to persistent stress-related anhedonic-like behavior? Amygdalo-hippocampal interactions appear to be necessary for the recall of rewardrelated contextual stimuli (Fuchs et al., 2007); thus, persistent stress-related reorganization resulting in fewer synaptic contacts may obscure reward sensitivity in part via hippocampaldependent memory processes. Such a model is consistent with hippocampal atrophy in depression, where anhedonia is a core feature (Sheline et al., 1999). 


\section{Prefrontal cortical dendritic spines reorganize in response to CORT}

CORT exposure also eliminated dendritic spines in layer V ILc, consistent with previous reports from layers II/III (Radley et al., 2008) and V (Liu and Aghajanian, 2008) medial prefrontal cortex. Remarkably little is known, however, regarding stress-related structural modifications in the oPFC, with the exception that Liston et al. (2006) reported dendritic arbor elaboration after chronic restraint stress. Spines were not enumerated; however, we report dendritic spine elimination that persists despite a "recovery" period. With the caveat that only CORT was manipulated here, we suggest that stress-related oPFC dendritic growth may serve as a compensatory response to spine elimination, since a long, sparsely populated dendrite could house as many spines as a short, densely populated dendrite (Bourne and Harris, 2011). In this case, dendritic elaboration would preserve total spine number. The stressor protocol used by Liston et al. (2006) impaired rats' attentional function but spared the reward-related reversal learning canonically associated with oPFC structural integrity. By contrast, other stressor protocols impair reversal learning (Cerqueira et al., 2007; Lapiz-Bluhm et al., 2009); thus, dendritic elaboration observed by Liston may reflect a protective response to stressor exposure that preserved behavioral function.

This interpretation implies a high degree of spine instability in response to stress hormone exposure, consistent with reports of diminished oPFC brain-derived neurotrophic factor (bdnf) mRNA expression after CORT (Gourley et al., 2009a) and evidence that postnatal cortical BDNF deficiency destabilizes dendritic spines (Vigers et al., 2012). BDNF is among a constellation of proteins that stabilize cortical neural structure during postnatal development. p190RhoGAP is another such regulator; through interactions with the Abl-related gene, it localizes to cellular membranes and inhibits the RhoA GTPase (Bradley et al., 2006). In the absence of these critical intracellular interactions, synapses are eliminated and spine heads fail to mature during late postnatal development, corresponding to adolescence in humans (Sfakianos et al., 2007). Hence, we tested p190rhogap ${ }^{+/-}$mice for corticosteroid vulnerability. Naive p190rhogap ${ }^{+1-}$ mice did not display anhedoniclike behavior, but they developed anhedonic-like sucrose neglect after prolonged exposure to a subthreshold concentration of CORT. In concert, oPFC spines were eliminated, suggesting that this loss confers vulnerability to depression symptomatology, likely by disrupting orbital networks implicated in reward sensitivity (for further discussion, Lapiz-Bluhm et al., 2009; Gourley et al., 2009b).

p190rhogap ${ }^{+/+}$mice exposed to subthreshold CORT had higher oPFC, although not hippocampal spine densities, and did not develop anhedonic-like behavior. This pattern suggests that p190RhoGAP-mediated Rho inhibition, in response to corticosteroid exposure, subserves behavioral resilience. These results contribute to an emerging perspective largely from the drug addiction field that dendritic spine reorganization in response to pathological stimuli may in some circumstances have adaptive consequences. For example, pharmacological blockade of cocaine-induced dendritic spine reorganization in the nucleus accumbens and oPFC increases, rather than occludes, sensitivity to subsequent cocaine exposures (Toda et al. 2006; Gourley et al., 2012).

By inhibiting Rho, p190RhoGAP brakes cellular actomyosin contractility in multiple biological contexts. In neural systems, it also coordinates behaviorally adaptive outcomes-learning about novel environments or stimuli (Lamprecht et al. 2002; Sfakianos et al., 2007) and mitigating vulnerability to stress hormone exposure or drugs of abuse (Fig. 3; Gourley et al., 2012). There are no current pharmacological agents that amplify p190RhoGAP activity, but our experiments add to mounting evidence supporting a shift toward therapeutic approaches to stress-related mood disorders that impact cytoskeletal outcomes. These include agents that target actin cytoskeletal regulators directly, or those that act indirectly - for example, ketamine, an NMDA receptor antagonist, has rapid antidepressant-like properties that are in part attributed to dendritic spine proliferation in deep-layer prefrontal cortex (Li et al., 2010). Our current findings suggest these structural modifications promote depression recovery through stressor resilience.

\section{References}

Arthur WT, Petch LA, Burridge K (2000) Integrin engagement suppresses RhoA activity via a c-Src-dependent mechanism. Curr Biol 10:719-722. CrossRef Medline

Bourne JN, Harris KM (2011) Coordination of size and number of excitatory and inhibitory synapses results in a balanced structural plasticity along mature hippocampal CA1 dendrites during LTP. Hippocampus 21:354-373. CrossRef Medline

Bradley WD, Hernández SE, Settleman J, Koleske AJ (2006) Integrin signaling through Arg activates p190RhoGAP by promoting its binding to p120RasGAP and recruitment to the membrane. Mol Biol Cell 17:48274836. CrossRef Medline

Brouns MR, Matheson SF, Hu KQ, Delalle I, Caviness VS, Silver J, Bronson RT, Settleman J (2000) The adhesion signaling molecule p190 RhoGAP is required for morphogenetic processes in neural development. Development 127:4891-4903. Medline

Cerqueira JJ, Mailliet F, Almeida OFX, Jay TM, Sousa N (2007) The prefrontal cortex as a key target of the maladaptive response to stress. J Neurosci 27:2781-2787. CrossRef Medline

Christian KM, Miracle AD, Wellman CL, Nakazawa K (2011) Chronic stress-induced hippocampal dendritic retraction requires CA3 NMDA receptors. Neuroscience 174:26-36. CrossRef Medline

Conrad CD, LeDoux JE, Magariños AM, McEwen BS (1999) Repeated restraint stress facilitates fear conditioning independently of causing hippocampal CA3 dendritic atrophy. Behav Neurosci 113:902-913. CrossRef Medline

Correll CM, Rosenkranz JA, Grace AA (2005) Chronic cold stress alters prefrontal cortical modulation of amygdala neuronal activity in rats. Biol Psychiatry 58:382-391. CrossRef Medline

Der-Avakian A, Markou A (2012) The neurobiology of anhedonia and other reward-related deficits. Trends Neurosci 35:68-77. CrossRef Medline

Feng G, Mellor RH, Bernstein M, Keller-Peck C, Nguyen QT, Wallace M, Nerbonne JM, Lichtman JW, Sanes JR (2000) Imaging neuronal subsets in transgenic mice expressing multiple spectral variants of GFP. Neuron 28:41-51. CrossRef Medline

Fuchs RA, Eaddy JL, Su ZI, Bell GH (2007) Interactions of the basolateral amygdala with the dorsal hippocampus and dorsomedial prefrontal cortex regulate drug context-induced reinstatement of cocaine-seeking in rats. Eur J Neurosci 26:487-498. CrossRef Medline

Gourley SL, Kiraly DD, Howell JL, Olausson P, Taylor JR (2008) Acute hippocampal BDNF restores motivational and forced swim performance after corticosterone. Biol Psychiatry 64:884-890. CrossRef Medline

Gourley SL, Kedves AT, Olausson P, Taylor JR (2009a) A history of corticosterone regulates fear extinction and cortical NR2B, GluR2/3, and BDNF. Neuropsychopharmacology 34:707-716. CrossRef Medline

Gourley SL, Koleske AJ, Taylor JR (2009b) Loss of dendrite stabilization by the Abl-related gene (Arg) kinase regulates behavioral flexibility and sensitivity to cocaine. Proc Natl Acad Sci U S A 106:16859-16864. CrossRef Medline

Gourley SL, Olevska A, Warren MS, Taylor JR, Koleske AJ (2012) Arg kinase regulates prefrontal dendritic spine refinement and cocaine-induced plasticity. J Neurosci 32:2314-2323. CrossRef Medline

Hernández SE, Settleman J, Koleske AJ (2004) Adhesion-dependent regulation of p190RhoGAP in the developing brain by the Abl-related gene (Arg) tyrosine kinase. Curr Biol 14:691-696. CrossRef Medline

Kolb B, Cioe J, Comeau W (2008) Contrasting effects of motor and visual spatial learning tasks on dendritic arborization and spine density in rats. Neurobiol Learn Mem 90:295-300. CrossRef Medline 
Lamprecht R, Farb CR, LeDoux JE (2002) Fear memory formation involves p190 RhoGAP and ROCK proteins through a GRB2-mediated complex. Neuron 36:727-738. CrossRef Medline

Lapiz-Bluhm MD, Soto-Piña AE, Hensler JG, Morilak DA (2009) Chronic intermittent cold stress and serotonin depletion induce deficits of reversal learning in an attentional set-shifting test in rats. Psychopharmacology 202:329-341. CrossRef Medline

Li N, Lee B, Liu RJ, Banasr M, Dwyer JM, Iwata M, Li XY, Aghajanian G, Duman RS (2010) mTOR-dependent synapse formation underlies the rapid antidepressant effects of NMDA antagonists. Science 329:959-964. CrossRef Medline

Liston C, Miller MM, Goldwater DS, Radley JJ, Rocher AB, Hof PR, Morrison JH, McEwen BS (2006) Stress-induced alterations in prefrontal cortical dendritic morphology predict selective impairments in perceptual attentional set-shifting. J Neurosci 26:7870-7874. CrossRef Medline

Liu RJ, Aghajanian GK (2008) Stress blunts serotonin- and hypocretinevoked EPSCs in prefrontal cortex: Role of corticosterone-mediated apical dendritic atrophy. Proc Natl Acad Sci U S A 105:359-364. CrossRef Medline

McEwen BS, Eiland L, Hunter RG, Miller MM (2012) Stress and anxiety: Structural plasticity and epigenetic regulation as a consequence of stress. Neuropharmacology 62:3-12. CrossRef Medline

Morales-Medina JC, Sanchez F, Flores G, Dumont Y, Quirion R (2009) Morphological reorganization after repeated corticosterone administration in the hippocampus, nucleus accumbens and amygdala in the rat. J Chem Neuroanat 38:266-272. CrossRef Medline

Peters A, Kaiserman-Abramof IR (1970) The small pyramidal neuron of the rat cerebral cortex. The perikaryon, dendrites and spines. Am J Anat 127:321-355. CrossRef Medline

Pitkänen A, Pikkarainen M, Nurminen N, Ylinen A (2000) Reciprocal connections between the amygdala and the hippocampal formation, perirhinal cortex, and postrhinal cortex in rat: a review. Ann N Y Acad Sci 911: 369-391. CrossRef Medline

Radley JJ, Rocher AB, Rodriguez A, Ehlenberger DB, Dammann M, McEwen BS, Morrison JH, Wearne SL, Hof PR (2008) Repeated stress alters dendritic spine morphology in the rat medial prefrontal cortex. J Comp Neurol 507:1141-1150. CrossRef Medline

Sfakianos MK, Eisman A, Gourley SL, Bradley WD, Scheetz AJ, Settleman J, Taylor JR, Greer CA, Williamson A, Koleske AJ (2007) Inhibition of Rho via Arg and p190RhoGAP in the postnatal mouse hippocampus regulates dendritic spine maturation, synapse and dendrite stability, and behavior. J Neurosci 27:10982-10992. CrossRef Medline

Sheline YI, Sanghavi M, Mintun MA, Gado MH (1999) Depression duration but not age predicts hippocampal volume loss in medically healthy women with recurrent major depression. J Neurosci 19:5034-5043. Medline

Sousa N, Lukoyanov NV, Madeira MD, Almeida OFX, Paula-Barbosa MM (2000) Reorganization of the morphology of hippocampal neurites and synapses after stress-induced damage correlates with behavioral improvement. Neuroscience 97:253-266. CrossRef Medline

Swanger SA, Yao X, Gross C, Bassell GJ (2011) Automated 4D analysis of dendritic spine morphology: applications to stimulus-induced spine remodeling and pharmacological rescue in a disease model. Mol Brain 4:38. CrossRef Medline

Tashiro A, Minden A, Yuste R (2000) Regulation of dendritic spine morphology by the Rho family of small GTPases: Antagonist roles of Rac and Rho. Cereb Cortex 10:927-938. CrossRef Medline

Tata DA, Anderson BJ (2010) The effects of chronic glucocorticoid exposure on dendritic length, synapse numbers and glial volume in animal models: implications for hippocampal volume reductions in depression. Physiol Behav 99:186-193. CrossRef Medline

Toda S, Shen HW, Peters J, Cagle S, Kalivas PW (2006) Cocaine increases actin cycling: effects in the reinstatement mode of drug seeking. J Neurosci 26:1579-1587. CrossRef Medline

Vigers AJ, Amin DS, Talley-Farnham T, Gorski JA, Xu B, Jones KR (2012) Sustained expression of brain-derived neurotrophic factor is required for maintenance of dendritic spines and normal behavior. Neuroscience 212: 1-18. CrossRef Medline

Vyas A, Mitra R, Shankaranarayana Rao BS, Chattarji S (2002) Chronic stress induces contrasting patterns of dendritic remodeling in hippocampal and amygdaloid neurons. J Neurosci 22:6810-6818. Medline

Wellman CL (2001) Dendritic reorganization in pyramidal neurons in medial prefrontal cortex after chronic corticosterone administration. J Neurobiol 49:245-253. CrossRef Medline

Woolley CS, Gould E, McEwen BS (1990) Exposure to excess glucocorticoids alters dendritic morphology of adult hippocampal pyramidal neurons. Brain Res 225-231. CrossRef Medline 